\title{
Evaluation of usefulness of mass flow meter to the survey of SI engine cylinder filling in one working cycle
}

\begin{abstract}
The article presents the technique of the usage of mass flow meter to the fill survey of a cylinder in the multicylinder engine, in each working cycles. The result of correctness of the survey was grounded on the comparison of air masses: the one registered with the usage of the flow meter and the other one calculated on the basis of mixture parameters. The flow meter was located in the consolidated part of suction system in front of the throttle valve. Mixture parameters were determined on the basis of time of fuel injection and measured $\lambda_{\mathrm{zm}}$ factor of burnt mixture. The studies were carried out in the whole operating range of engine. Discrepancies between the measured and calculated values for $93 \%$ of all of the cycles fall within the ambit of $\pm 3 \%$ of the actual value.
\end{abstract}

Key words: SI engine, the fill survey, mass flow meter, the phase of fill survey

\section{Introduction}

Filling with the air of particular cylinders of multicylinder SI engine is inimitable in further working cycles. Its reason is a string of hard- and nonmeasurable phenomena e.g. outflow of fresh air parts to the outlet manifold during the valve overlap.

In the present article the following question was formed: Is it possible, with the usage of mass flow meter located in front of the throttle valve, to measure with requested correctness the air mass flowing to any cylinder in each of the working cycles. There was also a trial conducted of determining the correctness with which it is possible to measure the filling of this cylinder. Due to it the assumption was adopted that despite several nonmeasurable phenomena influencing the filling, the air mass suck to the cylinder is going to be proportional to the one measured with flow meter.

It enabled the implementation of proportionality factor between measured and actual air mass, called the $\mathrm{k}$ correction factor. Therefore, the $\mathrm{k}$ correction factor ought to be used to revise measured air mass to reach its actual value, i.e. the air mass suck to the cylinder.

Non-zero response time of flow meter and phenomena occurring in the suction system dictate to assume that the correction factor of measured air mass is going to have different values for each of the points of engine work. The decisive parameters from which the value of correction factor depends on are: $\mathrm{n}$ rotational speed and angle of the $\alpha$ throttle valve. Along with the change of $\mathrm{n}$ rotational speed wave phenomena in the suction system change as well and thereby the filling of engine cylinders. They also influence on flow meter indications located under the throttle valve. The location of the throttle valve influences on repression of flow and its pulsations. Therefore, decisive meaning of the opening angle of the $\alpha$ throttle valve to the $\mathrm{k}$ correction factor comes from it. Named parameters, i.e. $\mathrm{n}$ and $\alpha$, also influence on the delay of signal of air mass flow $m_{a}$ rate in proportion to the air flow filling the engine cylinder. Therefore, these parameters decide about the range in which on the basis of $\mathrm{m}_{\mathrm{a}}$ signal the air mass is measured. In terms of above phenomena the method of air mass survey flowing to any cylinder in every filling and the way of their verification were developed.

\section{The method of air mass survey and its verification}

Presented method is used to the air mass survey filling a cylinder of four-cylinder SI engine by way of mass flow meter located in the consolidated part of suction system in front of the throttle valve. The essence of this survey method was graphically presented on the basis of signal processes in the Fig. 1. This picture shows signals in the system of controlling SI engine necessary to determining air mass in further and successive working cycles.

The survey consists of several phases. The first one determines once every turn in TDC piston: $\mathrm{n}$ rotational speed of engine and opening angle of the $\alpha_{\mathrm{zm}}$ throttle valve according to the dependencies:

$$
\mathrm{n}=\frac{60000}{\mathrm{t}_{0}}
$$

where: $\mathrm{t}_{0}$ - time of rotation

$$
\alpha_{\mathrm{zm}}=\frac{\sum \alpha}{\text { l.p. }}
$$

where: 1.p. - number of samples of $\boldsymbol{\alpha}$ signal.

Just before the opening of inlet valve the angle of the beginning of phase of $\phi_{\mathrm{pn}}$ fill survey is determined. For the engine which the studies were made on it is the angle of $672^{\circ}$ of the previous cycle. Its value is read from a „map" on the basis of rotational speed and opening angle of the throttle valve. In the moment of the accomplishment with crankshaft the $\phi_{\mathrm{pn}}$ location the $\mathrm{M}_{\mathrm{Azm}}$ air mass survey flowing to the engine cylinder begins which finishes half of the rotation later. $M_{\mathrm{Azm}}$ survey is an integration after the time of signal of air mass flow $\mathrm{m}_{\mathrm{a}}$ rate according to the formula:

$$
\mathbf{M}_{\mathrm{Azm}}=\int_{\phi_{\mathrm{pn}}}^{\phi_{\mathrm{pn}}+180} \mathrm{dm}_{\mathrm{a}} \mathrm{dt}
$$

It is equivalent with determining a zone under the curve of $m_{a}$ strength (in the Fig. 1 - bold with the half of the skyblue curve) in the designated borders. Simultaneously durance of injection pulses of engine is measured and after the finishing the each of them a mass of injected fuel is calculated. 


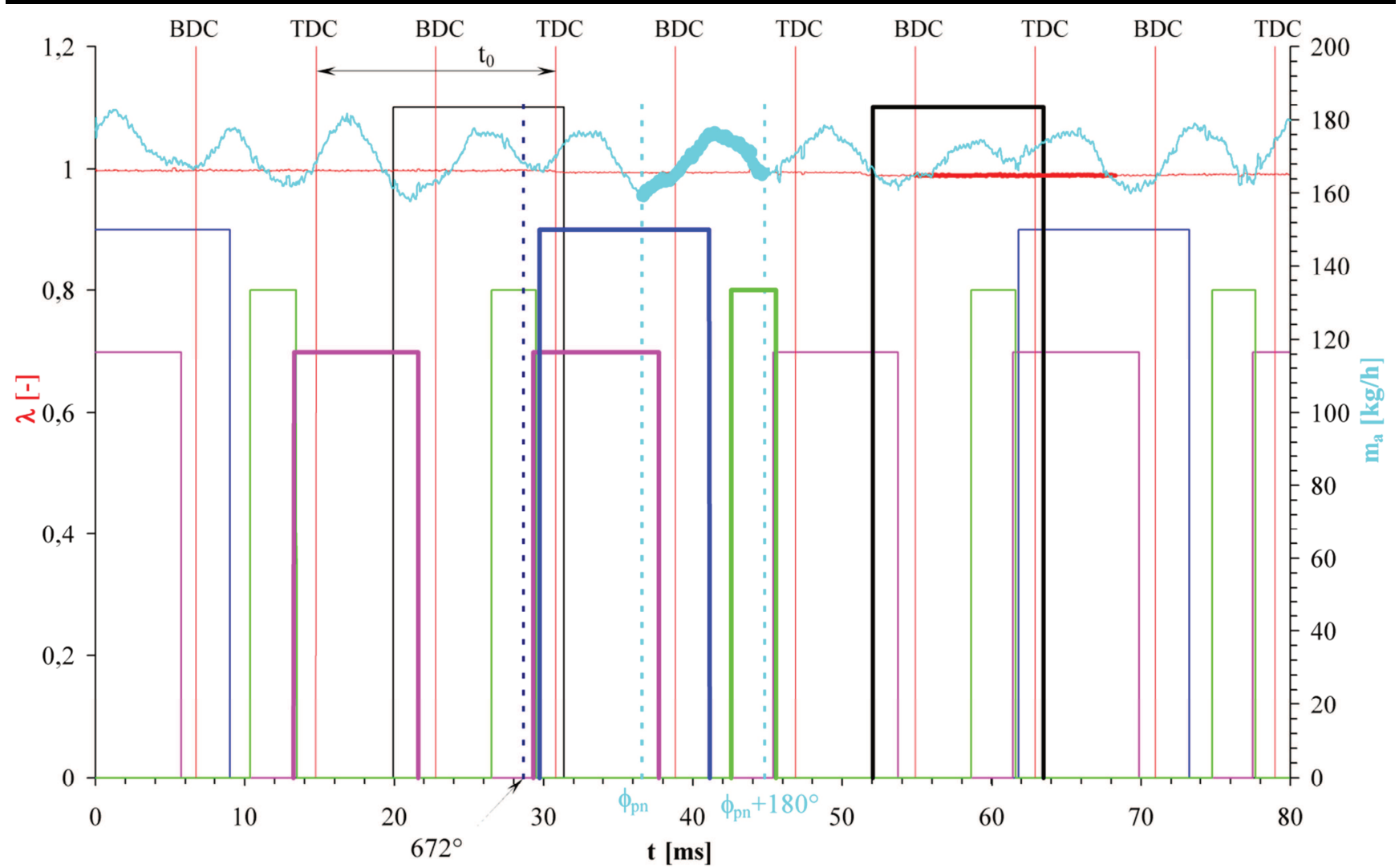

Fig. 1. Processes of chosen signals in the control system of SI engine necessary to determining air mass in each of the cycles of chosen cylinder

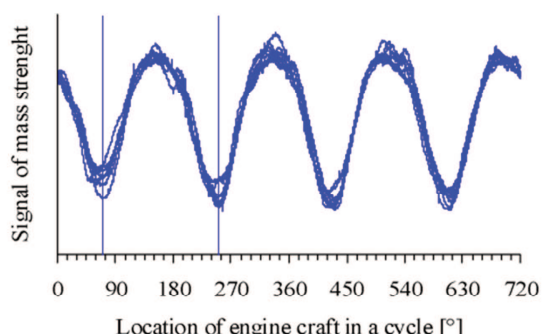

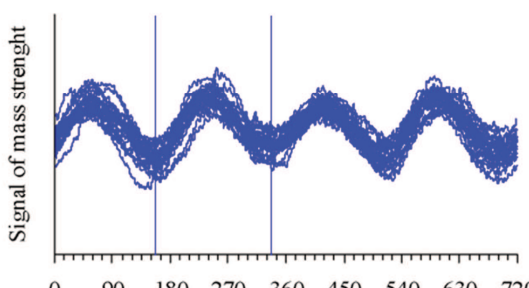

$\begin{array}{lllllllll}0 & 90 & 180 & 270 & 360 & 450 & 540 & 630 & 720\end{array}$ Location of engine craft in a cycle $\left[{ }^{\circ}\right]$
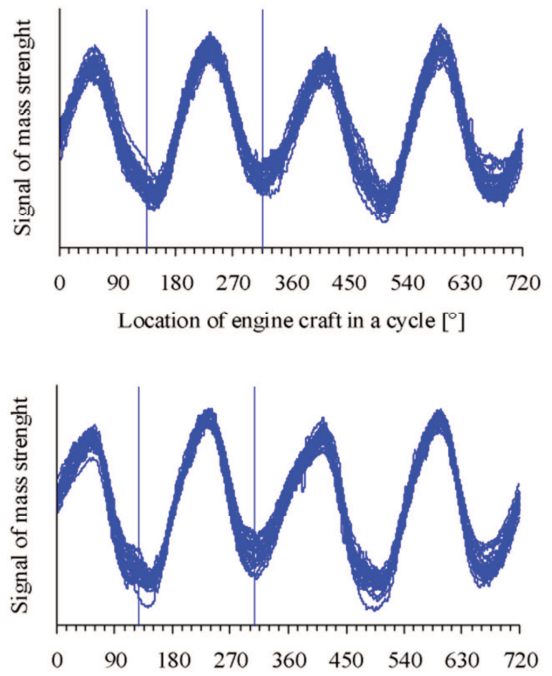

Location of engine craft in a cycle $\left[^{\circ}\right]$
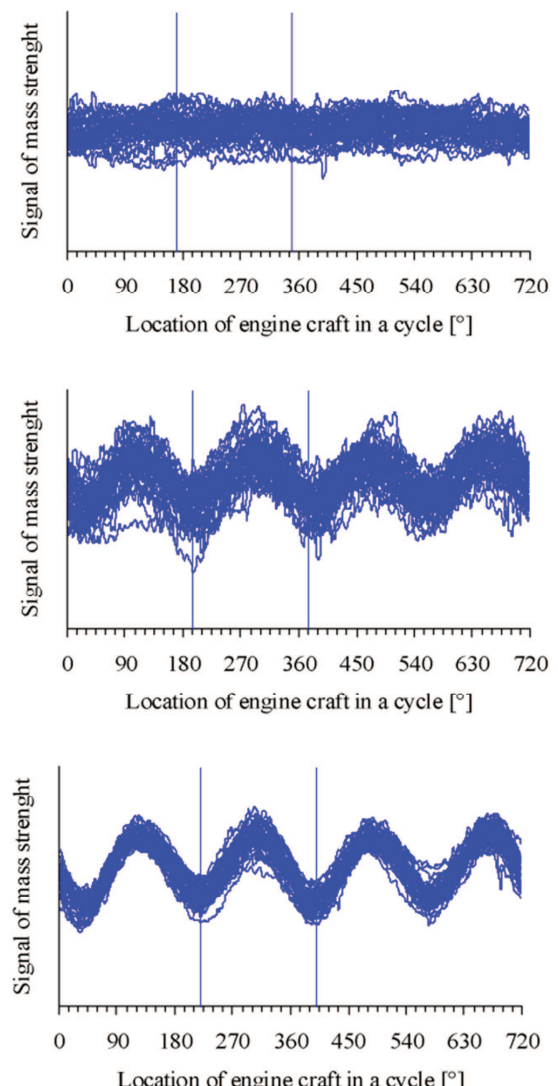

Fig. 2. Timing of $m_{a}$ signal of the function of crankshaft for different rotational speeds and openings angle of the throttle valve (in the columns: ,small”, „medium”, ,big” rotation speed; in the rows: „,small”, ,,medium”, ,big” opening angle of the throttle valve) 


$$
\mathrm{t}_{\mathrm{w}}=\mathrm{t}_{\mathrm{w} 2}-\mathrm{t}_{\mathrm{w} 1}
$$

where: $t_{w}$ - time of injection, $t_{w 1}$ - time of the beginning of injection, $t_{\mathrm{w} 2}$ - time of the finishing of injection

$$
\mathrm{M}_{\mathrm{F} 1 ; \mathrm{F} 2}=1.842 \cdot \mathrm{t}_{\mathrm{w}}-1.411
$$
cycle.

Each of the injections is assigned to particular working

The fuel injected during the opening of $\mathrm{M}_{\mathrm{F} 2}$ inlet valve (in the Fig. 1 it is a range shown with the bold blue line) and during the injection on the closed inlet valve in the previous $\mathrm{M}_{\mathrm{F} 1}$ cycle (in the Fig. 1 these are pulses shown with the bold pink line) creates fueled-airy mixture with the air which mass was measured in specific cycle.

$$
\mathrm{M}_{\mathrm{F}}=\mathrm{M}_{\mathrm{F} 1}+\mathrm{M}_{\mathrm{F} 2}
$$

where: $\mathrm{M}_{\mathrm{F}}-$ mass of injected fuel per a cycle, $\mathrm{M}_{\mathrm{F} 1}-$ mass of the first injection of fuel in a cycle, $\mathrm{M}_{\mathrm{F} 2}-$ mass of the second injection of fuel in a cycle.

As a result of burning of mixture exhaust gas are going to appear which analysis will allow to determine $\lambda$ factor of burnt mixture. The exhaust gas will drain during the opening of exhaust valve (in the fig. 1 it is a range shown with the bold black line). The average value of $\lambda$ signal from the analyzer (bold part of red curve) equals the $\lambda_{\mathbf{z m}}$ factor of burnt mixture in particular cycle according to the formula:

$$
\lambda_{\mathrm{zm}}=\frac{\sum_{540^{\circ}}^{120^{\circ}} \lambda}{\text { l.p. }}
$$

where: 1.p. - number of $\lambda$ signal samples in the range of counting the average, i.e. from $540^{\circ}$ of particular cycle to $120^{\circ}$ of the following one.

The delay with which the average value of $\lambda$ signal in proportion to the range of the opening of exhaust valve is calculated results from the time necessary for the outflow of exhaust gas and their analysis.

On the basis of fuel mass in particular cycle and $\lambda$ factor of mixture in the same cycle $\mathrm{M}_{\mathrm{Ao}}$ air mass as an actual air mass was measured according to the formula:

$$
\mathrm{M}_{\mathrm{Ao}}=\mathrm{M}_{\mathrm{F}} \cdot 14,7 \cdot \lambda_{\mathrm{zm}}
$$

The proportion of calculated $\mathrm{M}_{\mathrm{A} 0}$ mass to measured $\mathrm{M}_{\mathrm{Azm}}$ mass equals the $\mathrm{k}$ correction factor:

$$
\mathrm{k}=\frac{\mathrm{M}_{\mathrm{Ao}}}{\mathrm{M}_{\mathrm{A}_{\mathrm{zm}}}}
$$

The presented method of the air survey was developed as a result of the observation of influence of rotational speed and the opening angle of the throttle valve on the process of flow meter signal. It was observed that these borders submit to displacement along with the rotational speed of engine and the opening of the throttle valve. This displacement is different for the particular points of engine work and is connected with wave phenomena in the suction system. It was also noticed that for each of the points of engine work variability time of $\mathrm{m}_{\mathrm{a}}$ signal equals $180^{\circ}$ of rotation of crankshaft. Therefore, this signal was plotted in many points involving the entire zone of engine work and the angle of the beginning of the $\phi_{\mathrm{pn}}$ fill survey phase was determined in each of them (Fig. 2).

The angle of the end of the fill phase is located $180^{\circ}$ further. It is a result of this that flow meter signal during a cycle (two rotations - four filling of cylinders) holds four characteristic parts of process. They represent the fillings of the following four engine cylinders. On the basis of $\phi_{\mathrm{pn}}$ value in many points of work there was created a „map” of this angle for tested engine cylinder as dependency from $n$ rotational speed and $\alpha_{\mathrm{zm}}$ opening angle of the throttle valve (Fig. 3).

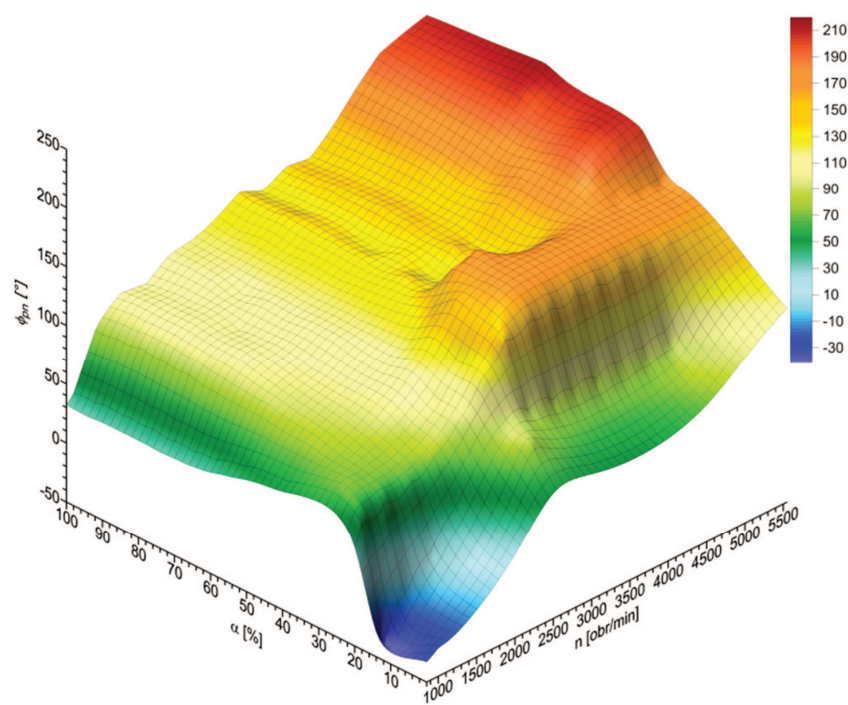

Fig. 3. „Map” of fill survey phase

Similarly, i.e. for many points of engine work there was created a ,map" of the k correction factor (Fig. 4) determining its value according to the dependency (9).

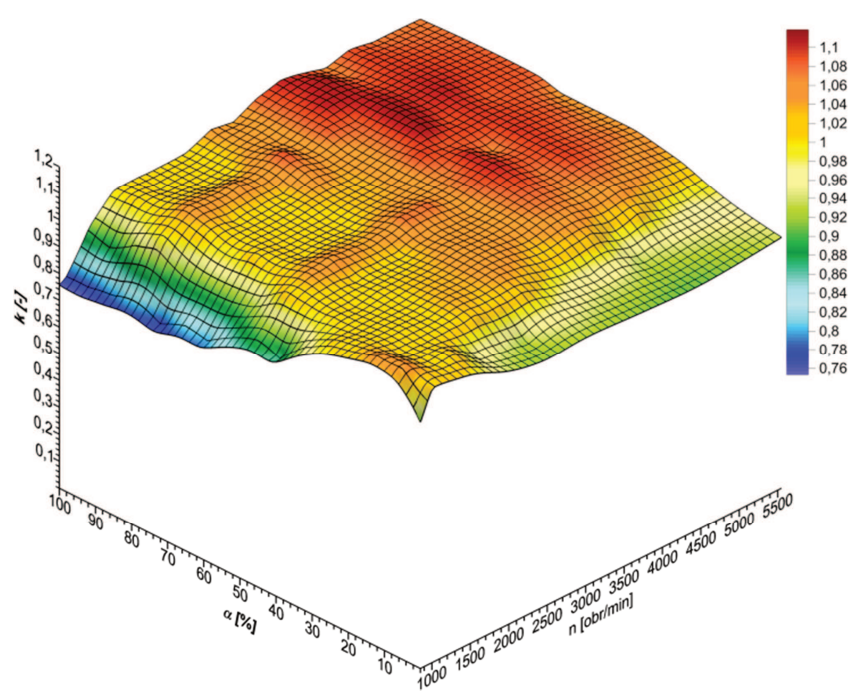

Fig. 4. „Map” of the k correction factor 


\section{Studies}

In order to develop the map: the angle of the beginning of the $\phi_{\mathrm{pn}}$ fill survey phase and the k correction factor and determining an error of air mass survey with the use of mass flow meter the studies were planned and carried out. The measurement site was built (Fig. 5).

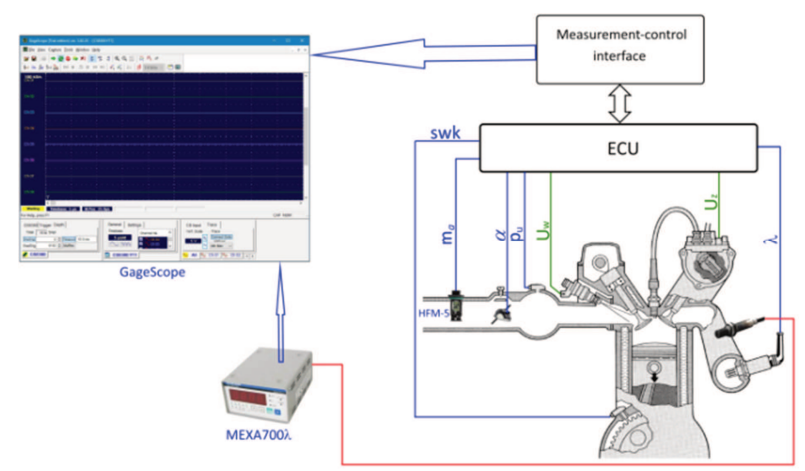

Fig. 5. Measurement site

Manufactured in series SI engine with multipoint, indirect injection of fuel with the capacity of $1600 \mathrm{~cm}^{3}$ was the object of study. It was installed on the stationary measurement site and was managed with the factory control system. Control system was equipped with measuring-controlling interface enabling a survey of all of the signals occurring in it. Interface belongs to the equipment of measurement site. Furthermore in the suction system of engine between air filter and throttle valve additionally HFM-5 mass flow meter of BOSCH company was installed. The broadband lambda sensor was the second additional sensing device installed. It was used as a sensing device of analyzer of the composition of MEXA700 $\lambda$ burnt mixture of HORIBA company. It was installed in the branch of outlet manifold of the fourth cylinder.

The PC computer equipped with the OCTOPUS CS8380 measuring card with eight measuring channels and GageScope software of GAGE company was used to the registration of any signals in the time function. Each of the measuring channels is equipped fourteen-bit A/D converter. The studies were carried out on the entire zone of points of engine work determined with the rotational speed and the opening angle of the throttle valve, i.e. in 215 points (Fig. 6).

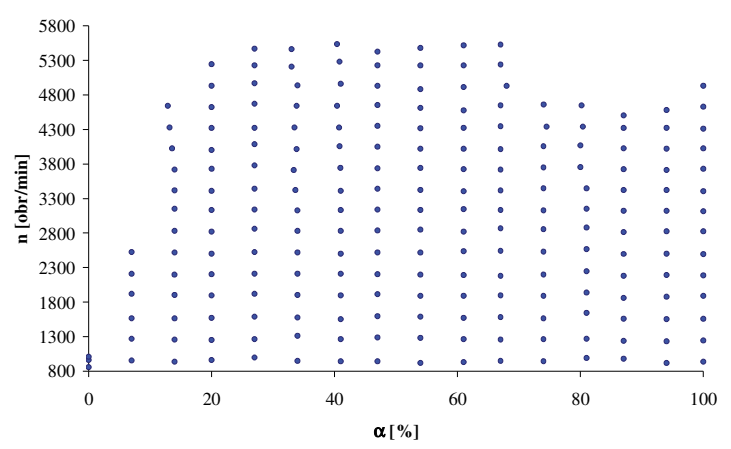

Fig. 6. Points of engine work in which the studies were carried out

Signals mentioned below were being registered in every point. They were sampled by $10 \mu$ s during $1 \mathrm{~s}$, i.e. one hundred thousands of samples of every signal. The following voltage signals in the function of time were registered (Fig. 7):

$-\lambda-$ composition of burnt mixture measured in the branch of outlet manifold of the fourth cylinder.

- $\mathrm{m}_{\mathrm{a}}$ - air mass flow rate

- $\mathrm{p}_{\mathrm{u}}$ - negative pressure in the intake manifold

$-\alpha-$ angle of the throttle valve measured with TPS sensing device which is a part of the control system

- $\mathrm{M}$ - torque on the brake shaft

- $U_{w}$ - voltage signal of controlling the power of injector of the first or the fourth cylinder

- $U_{z}$ - voltage signal of controlling the current in the primary winding of ignition coil for the first and the fourth cylinder

- swk - transformed with equipment into the bistate signal of the location of engine crankshaft.

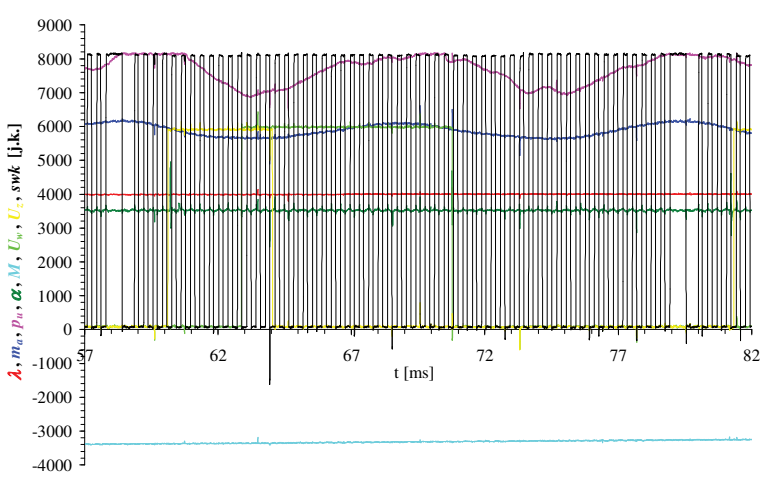

Fig. 7. Exemplary process of registered signals

\section{The results of studies}

Registered in the studies signals were submitted for initial modifications in order to prepare them for further analysis:

- bistate signals: $U_{w}, U_{z}$, swk were transformed into zero-one signals (Fig. 8)

- the remaining signals (analogue ones) were averaged with the use of method of average from 20 samples (Fig. 9)

- on the basis of the swk zero-one signal the angle of the location of shaft in the working cycle $\left(0-720^{\circ}\right)$ was assigned to every sample of registered signals (Fig. 10).

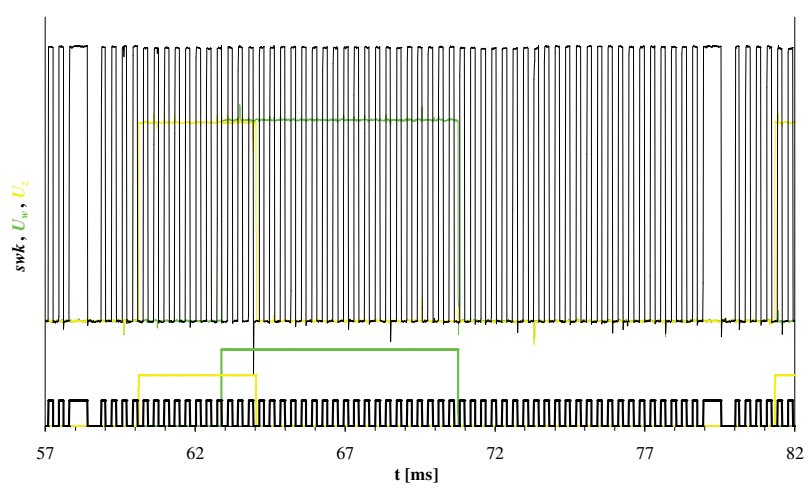

Fig. 8. Bistate signals before and after transformations into zero-one signals (on the upper part of figure registered bistate signals, on the lower part corresponding to the zero-one signal) 


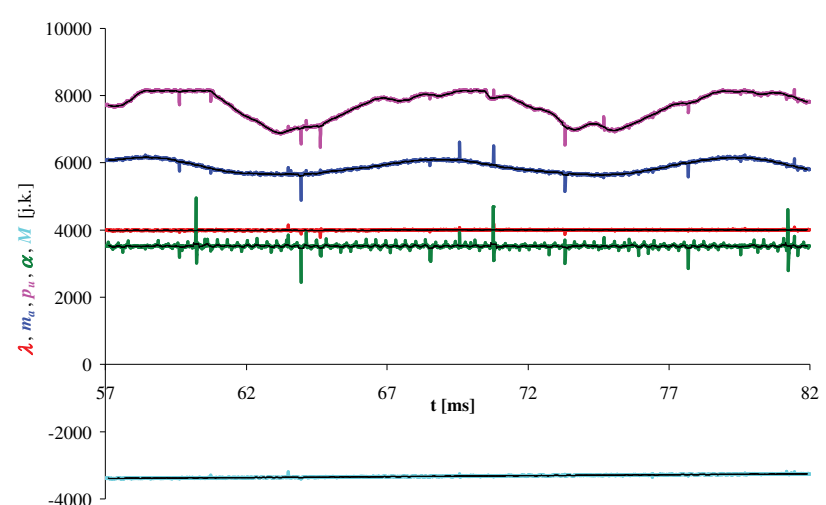

Fig. 9. Analogue signals before and after averaging with the use of method of average from 20 samples (black lines represent averaged processes)
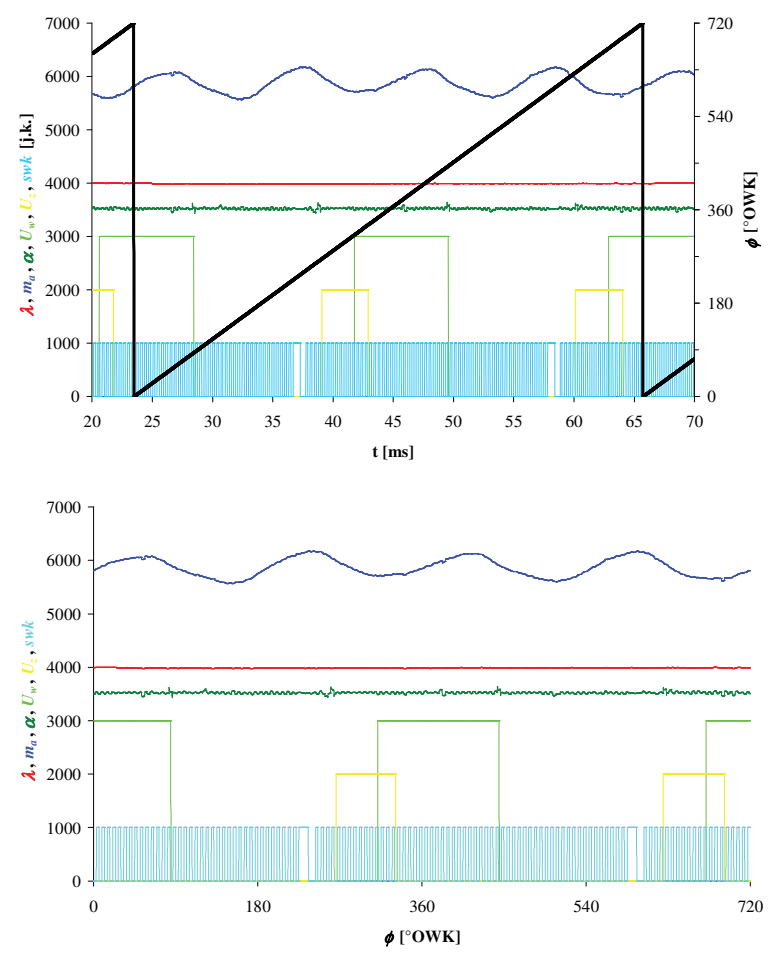

Fig. 10. Assignment of registered in time samples of signals to temporary angular position of engine shaft (chart above presents value of angle of $\phi$ crankshaft in a cycle against the background of registered in time samples of signals, chart below present the same samples of signals in the function of $\phi$ angle)

Modifications mentioned above enabled carrying out of analysis of registered signals for every entire working cycle. This analysis consists in determining all of the parameters of a cycle necessary to the calculation of air mass on the basis of $\mathrm{m}_{\mathrm{a}}$ signal and error of determination of this mass. They are:

- $\mathrm{n}$ rotational speed [rpm] for a rotation (from TDC to TDC) on the basis of swk according to (1),

- angular location of the $\alpha_{\mathrm{zm}}[\%]$ throttle valve on the basis of signal from TPS ( $0 \%$ - entirely closed, $100 \%$ entirely open] according to (2),

- the opening angle of $\phi_{\mathrm{pn}}$ and the end of $\phi_{\mathrm{pn}}+180^{\circ}$ of the phase of air mass survey $\left[^{\circ}\right]$ (retrieved from „map” on the basis of $\mathrm{n}$ and $\alpha_{\mathrm{zm}}$ ),
- time of injection of $t_{w}$ fuel [ms] on the basis of $U_{w}$ signal and corresponding to this time dose of injected $\mathrm{M}_{\mathrm{F}}$ fuel [mg] according to (4), (5), (6),

- mass of measured $\mathrm{M}_{\mathrm{Azm}}$ air $\left[\mathrm{mg}\right.$ ] on the basis of $\mathrm{m}_{\mathrm{a}}$ signal from HFM-5 flow meter in designated borders of survey according to (3),

- measured value of excess air $\alpha_{\mathrm{zm}}$ [-] factor on the basis of $\lambda$ signal from MEXA700 $\lambda$ meter according to (7),

- measured air mass $\mathrm{k} \cdot \mathrm{M}_{\mathrm{Azm}}$ rectified with the correction factor.

Later on air masses were compared: the measured one with the actual one and the error of survey in every entire registered cycle was calculated according to the formula:

$$
\delta_{\mathrm{M}_{\mathrm{A}}}=\frac{\mathrm{k} \cdot \mathrm{M}_{\mathrm{zm}}-\mathrm{M}_{\mathrm{Ao}}}{\mathrm{M}_{\mathrm{Ao}}} \cdot 100 \%
$$

The results of this error are shown in the Fig. 11.

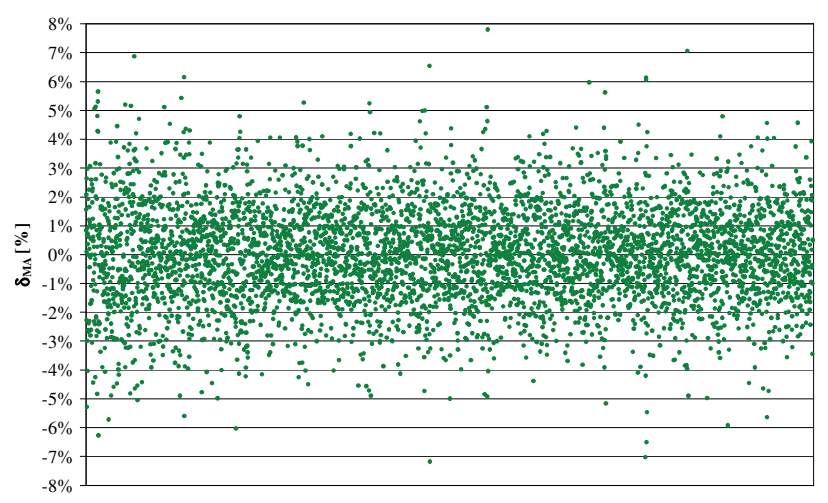

Fig. 11. Errors of air mass survey suck to the studied engine cylinder

Every point in the picture represents the value of error of air mass survey in one filling cycle. The picture includes values of error of survey for 4895 filling cycles.

The number of cycles for particular ranges of error was shown in the Fig. 12. Cycles in which error of survey is bigger than $3 \%$ represents less than $7 \%$ of all of them.

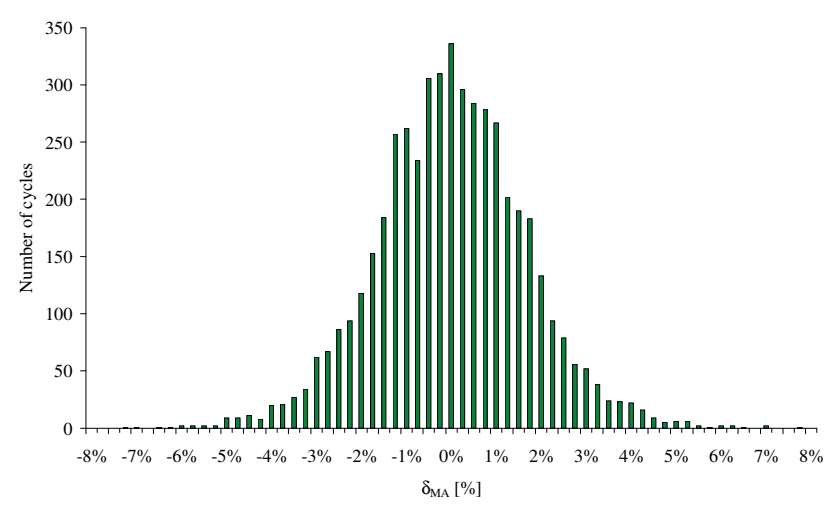

Fig. 12. Layout of the number of cycles for which error of survey falls within the ambit of particular borders

\section{Conclusions}

1. With the usage of mass flow meter located in the consolidated part of suction system in front of the throttle 
valve it is possible to measure air mass filling one engine cylinder in each of the working cycles.

2. The analysis of flow meter signal have to take place in the angular range of the rotation of crankshaft ancillary to the rotational speed of engine and the opening angle of the throttle valve.

3. For all of the analyzed work cycles from the entire zone of engine work the error of air mass survey did not pass $8 \%$.
4. Measuring air mass with the usage of presented method the error of survey is less:

- from $3 \%$ for $93 \%$ of cycles,

- from $4 \%$ for $98 \%$ of cycles,

- $\quad$ from $5 \%$ for $99,4 \%$ of cycles.

\section{Nomenclature}

SI spark ignition

n rotational speed

$\alpha \quad$ signal of location of the throttle valve

$\alpha_{\mathrm{zm}} \quad$ opening angle of the throttle valve

M moment on the brake shaft

$\mathrm{m}_{\mathrm{a}} \quad$ air mass flow rate

$\mathrm{M}_{\text {Azm }}$ measured air mass

$\mathrm{M}_{\mathrm{A} 0}$ actual air mass

$\phi \quad$ angular position of crankshaft in a cycle

$\phi_{\mathrm{pn}} \quad$ opening angle of the filling survey phase

$t_{w} \quad$ time of injection

$t_{w 1}$ time of the beginning of injection

$t_{\mathrm{w} 2}$ time of the finishing of injection
$\mathrm{M}_{\mathrm{F}} \quad$ fuel mass in a cycle

$\mathrm{M}_{\mathrm{F} 1}$ fuel mass injected in the first injection per a cycle

$\mathrm{M}_{\mathrm{F} 2}$ fuel mass injected in the second injection per a cycle

$\lambda$ signal of mixture composition with MEXA700 $\lambda$ analyzer

$\lambda_{\mathrm{zm}}$ measured value of mixture composition

$\mathrm{U}_{\mathrm{w}} \quad$ voltage signal of controlling the injector of the first or the fourth cylinder

$\mathrm{U}_{\mathrm{z}} \quad$ voltage signal of controlling the ignition coil for the first and the fourth cylinder

swk signal from the sensing device of crankshaft

$\mathrm{p}_{\mathrm{u}} \quad$ negative pressure in the intake manifold

\section{Bibliography}

[1] NITA, J. Niepowtarzalność cyklowego składu mieszanki w silniku GDI. Czasopismo techniczne. 2012, 5M, 229-241.

[2] PRZYBYŁA, G., POSTRZEDNIK S. Niepowtarzalność cykli pracy silnika przy jego wysokiej prędkości obrotowej oraz różnym obciążeniu. Czasopismo techniczne. 2008, 7M, 151-159.

[3] DYKIER, M., FLEKIEWICZ, M. Analiza częstotliwości drgań czynnika roboczego w układzie dolotowym silnika SI. Czasopismo techniczne. 2008, 8M, 173-183.

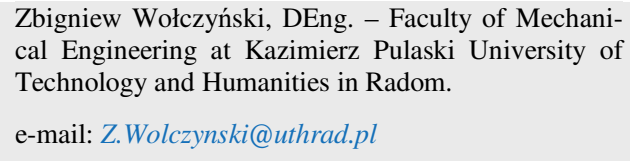

[4] NITA, J., WOŁCZYŃSKI Z. Ocena fluktuacji składu mieszanki wysterowanej z cyklu na cykl w silniku z pośrednim wtryskiem benzyny. Silniki Spalinowe. 2013, 3, 1002-1010.

[5] KOMORSKA, I. (red.) Eksperymentalna ocena możliwości poprawy sprawności silnika benzynowego zasilanego LPG poprzez optymalizację jego sterowania. UTH Radom. 2016, 18. 